\title{
LOS ACTOS DE OPOSICIÓN EN LA DISIDENCIA MAGISTERIAL EN CIUDAD JuÁrez, ChiHuAhua
}

OLIVERIO ISMAEL FERMAN ÁVILA

\section{RESUMEN}

1 n el capítulo se aborda, de manera breve, el producto de una investigación sobre los procesos que vive la disidencia magisterial en Ciudad Juárez, particularmente el movimiento RESISSSTE. El estudio se realizó en un marco de enfoque cualitativo y con un diseño metodológico fenomenográfico. Las indagaciones iniciaron un martes del mes de mayo en 2016 y se extendieron por un lapso de catorce meses para finalizar en el mes de julio de 2017. Este artículo pretende ser un acercamiento a RESISSSTE desde una perspectiva política e ideológica, que busca describir la naturaleza política de los actos contestatarios de la disidencia magisterial en Ciudad Juárez. El marco teórico referente partió de los aportes de la pedagogía crítica, las teorías de la reproducción y la teoría de la resistencia. Este acercamiento implica, por supuesto, un análisis de los anclajes ideológicos, experiencias de vida -tanto personales como profesionales- de docentes que participan en la disidencia magisterial organizada, pero, en particular, orientado a diferenciar, tal como lo supone McLaren (1998), entre las conductas de oposición y los mecanismos de resistencia que se delinean y se ponen en práctica en la disidencia magisterial ante las aspectos torales que planteó la 
Reforma Educativa peñista, entre estos: la formación y regulación del profesional docente -la evaluación y sus efectos en la estabilidad laboral-, y la implementación de un nuevo currículum, con las implicaciones normativas que implícita o explícitamente le subyacieron.

Palabras clave: hegemonía, ideología, resistencia, disidencia magisterial, actos de oposición.

\section{INTRODUCCIÓN}

El presente artículo es un acercamiento interpretativo crítico de los anclajes ideológicos y políticos de la disidencia magisterial en Ciudad Juárez, a partir de la resistencia, y teniendo definidos de manera clara los referentes teórico-prácticos sobre la pedagogía crítica y sus categorías conceptuales: hegemonía, poder, ideología, resistencia y emancipación permiten analizar y definir los actos contestatarios, así como diferenciar los actos de oposición de las acciones de la resistencia en el marco del caso RESISSSTE Ciudad Juárez.

Desde 2002, ante la falta de atención médica digna, ya que se pretendía establecer la clínica del ISSSTE en una casa-habitación al suroriente de la ciudad, un grupo de docentes comienza a aglutinarse en un frente de lucha que finalmente logra el compromiso y la posterior construcción del hospital de zona. Posteriormente, en 2004, con el planteamiento de la reforma del ISSSTE con la misma base de docentes en la resistencia, nace el movimiento RESISSSTE, en defensa de la escuela pública y las conquistas laborales del empleo. Desde esos ayeres y hasta la fecha, RESISSSTE ha liderado diversas sublevaciones hacia lo que ellos consideran que atenta contra los principios públicos y democráticos de la escuela, con diversos trasfondos tanto ideológicos como políticos de los docentes que han formado a lo largo de estos 15 años. 


\section{ESTRUCTURA METODOLÓGICA}

La investigación se realizó en el marco del enfoque cualitativo, que permite estudiar la realidad desde un contexto natural, lo cual otorga un sentido y representatividad de la cotidianidad y ayuda a interpretar los fenómenos de acuerdo con los significados que tienen para las personas implicadas. Tal y como sostienen Rodríguez, Gil y García (1996), la investigación cualitativa implica la utilización y recogida de una gran variedad de materiales, conversatorios, entrevistas, experiencia personal, historias de vida, observaciones, textos históricos, imágenes y sonidos que describen la rutina, las situaciones problemáticas y los significados en la vida de las personas. Se definió a la "fenomenografía" como la perspectiva metodológica que permite interpretar de mejor manera el fenómeno que atañe al objeto de investigación planteado. Según Álvarez-Gayou: "la fenomenografía se enfoca en las formas como son experimentados diferentes fenómenos y en las formas de percibirlos, conocerlos y tener habilidades relacionados con ellos" (2003, p. 89). Se establecieron tres técnicas principales para la recolección de datos: participante como observador (ÁlvarezGayou, 2003), la entrevista individual y el estudio de casos.

La vasta información empírica recabada fue organizada mediante un proceso exhaustivo de categorización: primero, como categorización abierta, lo cual permitió un acercamiento al material empírico y problematizarlo, definiendo patrones de coincidencia. Posteriormente, a través de una categorización axial en la que se organizó la información a partir de las recurrencias encontradas, lo que permitió definir categorías/dimensiones de análisis de los datos empíricos teniendo como referencia el marco teórico que sustenta esta indagación. La pregunta central que orientó la búsqueda de información es la siguiente: ¿cuál es la naturaleza política de los actos contestatarios de la disidencia magisterial en Ciudad Juárez?

Los datos empíricos se recabaron a partir de mi participación como observador, primero externo, luego como participante, en las asambleas que lleva a cabo RESISSSTE en Ciudad Juárez, que se 
realizan los martes de cada semana durante el ciclo escolar. Las asambleas se desarrollan en dos horas, aproximadamente, por lo cual no solo son datos amplios en cantidad, sino en cuanto a la profundidad de las discusiones desarrolladas en ellas.

La vinculación inicial para la realización de esta investigación se remonta al martes 4 de octubre de 2016. La participación como observador se extendió por las siguientes cuatro asambleas semanales en las que se tomaron notas sobre la forma de organización, conformación del grupo consolidado y liderazgo. El papel como participante activo se extendió desde el 15 de noviembre de 2016 al 30 de mayo de 2017.

\section{HALLAZGOS Y RESULTADOS}

Para presentar los resultados se organizó la información en seis apartados que se presentan a continuación.

\section{LOS ORÍGENES DE LA RESISTENCIA MAGISTERIAL EN CIUDAD JUÁREZ}

Resistencia, ideología, izquierda, chairos, satanización. Todos son calificativos que muy comúnmente son utilizados por las personas para referirse a la disidencia magisterial. Se puede hablar de diversos movimientos, no obstante, punto y aparte merece atención el movimiento de la rebelión en el estado de Chihuahua, Ciudad Juárez, RESISSSTE.

Vincularse con el movimiento fue una tarea relativamente sencilla. En las escuelas del nivel básico se habla de ellos. Algunos maestros mantienen amistad y/o vínculo profesional con algún docente que ha participado en algunas de las acciones del RESISSSTE en Ciudad Juárez desde 2004. Más adelante se abordará con detalle, y desde la perspectiva de los integrantes del movimiento, los pormenores de su conformación, estructura y acciones de resistencia. La conexión se dio por medio de un docente que participa como parte del grupo. Con él se iniciaron las indagaciones sobre las reuniones y las formas de organización. La respuesta fue rápida: el movimiento se reúne formalmente cada martes en 
una asamblea local que se concreta en el edificio de una primaria federalizada, en la que su director es participante aguerrido y uno de los líderes pujantes del alzamiento. Desde la primera visita como observador a la asamblea local, el grupo conoció las intenciones de participar como parte de un proceso de investigación sobre la disidencia magisterial en la ciudad.

La motivación inicial, en correspondencia con los objetivos de esta investigación, fue realizar un acercamiento a RESISSSTE desde una perspectiva política e ideológica, es decir, conocer qué hay detrás de los orígenes del movimiento, qué significa —desde una perspectiva sociológica- su fundación, qué papel juega la formación ideológica y política de los fundadores en el proceso de su surgimiento y consolidación.

Antes de penetrar en los análisis sobre el movimiento de la disidencia magisterial, sus orígenes y motivaciones, es de vital importancia partir del reconocimiento de la problemática que el escenario plantea. Ante la situación tan compleja y delicada que guardan las relaciones del capital con la acumulación de la riqueza, la consiguiente brecha entre los pocos que tienen mucho y los que cada vez más tienen muy poco, la explotación de los recursos naturales, la privatización de los sistemas de salud, la socialización de las deudas tanto gubernamentales como privadas, Martínez Escárcega (2005) destaca el pobre papel de la educación que ha sido reducido al ámbito psicopedagógico, dejando de lado el análisis de la escuela como un instrumento contradictorio de reproducción y transformación social, que a la vez ayuda a delinear y exacerbar las relaciones de explotación capitalista. No es raro encontrar que la disidencia magisterial, como parte de los movimientos sociales, tenga origen en la develación, en la mayoría de los casos inconsciente, de la opresión que es ejercida por el patrón sobre la clase trabajadora.

Concretamente, en el caso que nos ocupa, RESISSSTE tiene como punto de partida el descontento social en cualquier ámbito laboral. En muchos casos, y específicamente en México, el rol docente se ha ido transformado desde aquel apostolado hasta la visión de un empleado con habilidades técnicas limitadas, como 
es visto en la actualidad por las políticas neoliberales del costoeficiencia. En estas transformaciones -o más bien involucionesse destacan modificaciones laborales que buscan reorientar las relaciones obrero-patronal entre el docente y el Estado, como rector y garante de la educación pública. Estas modificaciones han significado para el docente la pérdida de derechos ya adquiridos y un menoscabo de su seguridad social, como lo destaca uno de los miembros del RESISSSTE:

...una de las grandes movilizaciones entre los maestros fue en el 2003 cuando se pretende hacer una clínica del ISSSTE en una casa particular, algo pues que no era aceptable para el magisterio, cómo íbamos [sic] a tener una clínica en una casa, y ahí nace o se confluye alguna gente que posteriormente en 2004 salimos a las calles. Ya con la incertidumbre de la privatización del ISSSTE, para 2007, que comenzamos a ver sus efectos para marzo de 2007 que se aplica la ley del ISSSTE...es cuando con esa problemática nosotros empezamos a denunciar estos atropellos (E1, 09/12/2016).

En concordancia con lo anterior y tal como lo sostiene Martínez:

Si se parte de que el actual enfoque educativo nada ha hecho en relación con los graves problemas de desigualdad económica en México, entonces se asume que la educación es el reflejo de las relaciones estructurales de la sociedad industrial moderna y que los críticos solo dan soluciones superficiales a una problemática que no han podido o querido identificar (2005, p. 17).

Son pocos los análisis realizados que atienden a las relaciones de poder que se desarrollan dentro de la escuela, las relaciones de desigualdad, la exclusión, el uso del poder como instrumento de castigo - por lo general, del maestro versus el alumno, pero cada vez más generalizado entre pares-, lo que dice el profesor, lo que no dice, cómo se organiza la dinámica escolar (filas de los alumnos de promedio 10 y filas de rezagados, o bien, actividades exclusivamente para hombres y otras - muy pocas - para mujeres), es 
decir, se sigue rindiendo culto, consciente o inconsciente, a los rituales que reproducen y perpetúan "los esquemas ideológicos con los que opera la sociedad” (Martínez, 2005, p. 18). La disidencia se nutre de la resistencia, o bien, la resistencia crea formas de disidencia; cualquiera que sea el caso, la ideología juega un papel decidido en los procesos que van dando origen a la resistencia en los movimientos sociales.

En Ciudad Juárez, el movimiento RESISSSTE tuvo sus orígenes en el grupo Tábano:

Llegan varios jóvenes, ex normalistas rurales, con experiencia de lucha que estaban trabajando en la sierra y llegaron ese año, llegaron aquí a Juárez, egresados del MEXE Hidalgo, maestras egresadas de Saucillo, Chihuahua, maestras egresadas de la Normal del Estado, críticas; hubo una coincidencia ideológica con los compañeros, que nos permitió consolidarnos y le damos vida, más vida al grupo de la CNTE, pero a la vez logramos establecer una coordinación con los otros maestros inquietos en el estado... [gente] de Parral, de Jiménez, de Saucillo, de Camargo, de Cuauhtémoc, de Chihuahua, y teníamos nuestras reuniones, cada dos meses o tres meses nos juntábamos en Delicias o en Jiménez, un núcleo grande ya de la Coordinadora Nacional de los Trabajadores de la Educación, en ese proceso estábamos cuando nos cae de sopetón la bronca de la reforma a la ley de ISSSTE. El movimiento de la ley del ISSSTE no fue un movimiento espontáneo, no, había un núcleo organizado en cada uno de los municipios que empezamos a trabajar coordinadamente y le dimos rumbo al movimiento, nos sorprendió la respuesta cultural en un momento de los compañeros porque había un congreso en Chihuahua y la gente se soltó fuerte, y a raíz de la bronca de la Reforma de la Ley Federal del ISSSTE, formamos RESISSSTE (E2, 05/02/2017).

RESISSSTE se reconoce como una estructura de lucha independiente, poco formal, pero que puede vincularse con los diferentes grupos de la disidencia magisterial, no solamente en el país, sino en las diferentes ciudades del estado de Chihuahua. Es constraestructural, antisistémico y contrahegemónico, y en- 
tre todo, pareciera que uno de sus primeros actos contestatarios radica en la propia organización interna. Dentro del movimiento se distinguen algunos líderes visibles, que han sido constantes con el paso de los años y que han abonado a su consolidación. Estos, reconocidos por los propios miembros del grupo, destacan que la ordenación de RESISSSTE, tanto a nivel local como en el estado, no tiene una distribución inamovible o vertical que tome decisiones, sino que el órgano máximo es la propia asamblea, de constitución colectiva y democrática. Sin embargo, se reconoce que existe un grupo mayormente comprometido con las causas. Uno de estos líderes reconoce que:

...existe un grupo más comprometido, de fuerte coincidencia ideológica, pero lo que me ha permitido observar a mí en estas sesiones es la forma de organizarse que es muy plural, que no tiene como una especie de liderazgo específico, sino que se va formando, se va construyendo la agenda, por así decirlo, y donde se van sumando la participación de los temas que van resultando en esta visión de la lucha de la resistencia...si los enemigos piensan que eliminando a ( $\mathrm{x}$ ó y) acabaron con el movimiento...nada más fuera de la realidad, el RESISSTE es un movimiento para quedarse y ocupa ya un papel en la historia de Ciudad Juárez (E2, 05/02/2017).

Desde la teoría marxista se reconoce la lucha de clases como el motor de la historia, y estas se definen necesariamente a partir del lugar que ocupan los individuos en las prácticas sociales. De acuerdo con Martínez Escárcega: "lo que define la pertenencia a una clase social es la actuación de los individuos respecto al ámbito material, político e ideológico" (2005, p. 24). Por tanto, las relaciones conflictivas entre las clases y la lucha de clases, continúa Martínez (2005), son relaciones de poder que resaltan la necesidad del análisis de otro ejercicio de poder que es el enfrentado. Las relaciones de poder se presentan, de forma necesaria, en la escuela, particularmente cuando el sistema educativo busca implantar una ideología acorde con los intereses del poder hegemónico. Este proceso de implantación implica distintas formas de imposición, 
autoritarismo, disciplina y control burocrático. Lo que antes se analizaba en relación con el docente-alumno, en virtud del primero como agente opresor, hoy los estudios se van trasladando de manera paulatina al ámbito de relación docente-sistema, teniendo a este último como el ejecutor de las políticas neoliberales de costobeneficio con una lógica mercantilista, lo que ha desencadenado acciones de resistencia magisterial a partir de la concienciación de su rol de oprimido.

\section{LA REFORMA PEŃISTA: LA ESCUELA PÚBLICA EN VENTA}

En las asambleas semanales se abordaron elementos de la reforma peñista: el movimiento privatizador, los proyectos educativos empleados por el gobierno-empresa como mecanismo de privatización, el lastre en la cancelación de derechos laborales obtenidos por los trabajadores de la educación, el tortuoso camino que se ha seguido para la profesionalización de los docentes nóveles y, por supuesto, los elementos de la calidad, panacea de todos los males educativos.

Tal como lo menciona uno de los docentes en las asambleas:

Parece que desde que nos quieren imponer la feforma todo gira en torno a la empresa... eso de las matemáticas constructivas, todos esos proyectos nuevos suenan muy empresariales... pues lo malo es que sacaron a los charros y metieron a la empresa, y no estábamos tan equivocados cuando decíamos en el análisis de la nueva estructura de loS SEECH... estos cabrones son empresarios y que caen a la perfección con el movimiento privatizador de la reforma... y vienen tan fuerte que no negociaron ninguna posición con los charros (A1, 15/11/2016).

Los docentes comentaron que en algunas zonas escolares ubicadas al suroriente de la ciudad han querido imponer el proyecto de matemáticas constructivas que ha sido impulsado por el Fondo Unido y alguna asociación civil vinculada con la Fundación del Empresariado Chihuahuense (FECHAC). Ante estos hechos, se 
muestran renuentes, porque, según se dice, en las zonas más marginadas los maestros suelen ser más combativos o apáticos ante lo que se muestre como una labor que requiera más trabajo. Parte de esa resistencia proviene de lo que reconocen como "movimiento privatizador", que ha afectado los derechos laborales adquiridos por los docentes y en el que el Sindicato Nacional de Trabajadores de la Educación (SNTE) ha sido cómplice y aliado del Estado Mexicano:

Es el mismo pinche proceso de privatización de cancelación de derechos y de la estabilidad laboral, pero ya los profes no dicen ni madre, es como los nuevos que están entrando ahorita al servicio, entran los nuevos y ven un estado normal, o sea [sic] su forma de contrato es normal, que no tengan seguridad social es normal, que los metan a exámenes es normal para ellos porque están viviendo ya con esta cultura nueva jodida (A3, 29/11/2016).

Se dice, pues, que los empresarios solamente están viendo dónde ganan, dónde pueden hacer más negocio, y es evidente que la educación pública no lo es, por lo que más allá de las bondades que comunica la nueva reforma a la sociedad, conlleva un proceso de maximización de la ganancia a partir de los ajustes que da la ambigüedad del proceso de la calidad total. En este asunto, el movimiento magisterial reconoce al sindicato oficial (SNTE) como parte del mecanismo de opresión que ha emprendido el Estado para tratar de imponer una reforma que lejos de la búsqueda del mejoramiento en los resultados del aprendizaje, busca regular y "apretar" las condiciones de trabajo de los docentes.

Cuando los primeros efectos punitivos de la reforma se hicieron evidentes, singularmente en el cese de docentes que no presentaron la evaluación como acto de protesta, los integrantes de RESISSSTE procuraron no negociar para posicionarse. Se trató de convencer a las docentes cesadas que presentaron denuncia ante la Junta de Conciliación y Arbitraje por despido injustificado para que cumplieran con la evaluación y, con independencia del 
resultado, gozaran de ser reinstaladas, eso sin dejar a un lado dar marcha atrás a la demanda:

Le dije al compañero del sindicato "no diga sandeces", el Servicio Profesional Docente no tiene la capacidad para reinstalarlos porque no es su patrón, ni puede retirar la demanda de despido... lo que sí puede hacer el SPD es contratarlos que no es lo mismo porque es tirar a la basura el contrato original, pero contratarte con nuevas reglas (A1, 15/11/2016).

Así, el panorama en los sistemas educativos no es para nada alentador, pues desde la lógica del mercado, las escuelas son lugares ineficientes, que no están logrando el retorno de la inversión. Los sectores dominantes del sector político pretenden implantar la dominación desde la escuela y que esta funcione según sus intereses, reforzar el carácter legitimador y hegemonizante de la educación pública y privada, y, lo más grave, someter al educador y al educando a través del conocimiento y legislación oficial. Este sometimiento asegura la eficiencia, y, desde luego la optimización de la ganancia, que es la lógica del mercado con la que se han acometido las más recientes reformas de los sistemas educativos del mundo, incluida por supuesta la reforma peñista.

En la función empoderadora de la escuela y sus agentes, uno de los objetivos de la pedagogía crítica alude a la resistencia como una práctica reflexiva para comprender procesos sociales emergentes tanto en la propia escuela como en otros espacios institucionales. En estos sitios, tal como lo menciona D'Antoni (2014), es frecuente observar la desobediencia de quienes se ven sometidos a prácticas opresoras. Es por ello que la pedagogía crítica debe ir más allá de la resistencia, debe ser emancipadora, "forjando sujetos críticos, propositivos, democráticos y conscientes de la necesidad de participar en la solución de los problemas que abruman a la comunidad, región, país. Sujetos conscientes de las deficiencias y limitaciones del modelo de desarrollo imperante" (p. 57), el cual promueve muy diversas formas de dominación. 


\section{EL ESTADO, LA IDEOLOGÍA OFICIAL Y LA IMPOSICIÓN PARA CON- TRARRESTAR LA OPOSICIÓN}

RESISSSTE analizó durante algunas sesiones la imposición en distintos puestos de la estructura del sistema educativo estatal, particularmente en Ciudad Juárez, posiciones que anteriormente se negociaban con el SNTE y que con el cambio de administración estatal se han apoderado de ellos personas muy ligadas al empresariado y/o asociaciones civiles vinculadas a la iniciativa privada. Estas actividades fueron observadas como un evidente camino para imponer la ideología oficial y favorecer el proceso de implantación de la Reforma Educativa que fue muy bien recibida por empresarios y el ala de centroderecha.

Dentro de esta categoría se destacaron en los datos empíricos varios patrones. El primero de ellos refiere a develar cómo las nuevas autoridades educativas se sirven de gente del sistema de la educación para matizar la empresarialización de la estructura, es decir, se puede ver en la designación de puestos la mano del secretario de educación - un conocido empresario- y la subsecretaria de educación de la zona norte, quien dirigió por algunos años una asociación civil, vinculada con el secretario. Si bien algunos puestos no fueron negociados con la cúpula sindical, deja de manifiesto que se "palomearon", pero la decisión vino desde la nueva estructura:

- Quien está moviendo los hilos para los puestos es esta señora Judith por su relación estrecha con Pablo Cuarón... y ves los pasillos y ves caras largas, lo que sí se puede ver es que les pegaron duro a los charros sindicales...

- Pues mi jefa se fue a la Coordinación de Secundarias Técnicas (se escucha otro aporte: pues puede ser una posición ganada por ella), pero ella sí es charrota, charrota.

- La gente que sí es de educación pues parece que, sí revisaron el perfil, pero ahora está peor, pues ya no nomás nos tenemos que cuidar de los charros sino de los empresa- 
rios... parece que le dieron mucha coba a los empresarios (A1, 15/11/2016).

En el análisis de los puestos políticos otorgados como forma de contrarrestar la oposición, los miembros del grupo analizaron la conveniencia de informar sobre la andanada de puestos de los SEECH que han sido copados por el SNTE e informar cuáles se dicen que son del RESISSSTE, estrategia que ha sido manejada como de golpe político al movimiento y, de esta manera, se ha detallado en la asamblea la estrategia política que debe que asumir la resistencia. En este se considera de igual importancia examinar el perfil de las autoridades educativas y destacar cuáles son afines al PAN y cuáles responden al SNTE y/u otros intereses. En alguna parte de ese proceso de imposición de una nueva ideología empresarial se consideró el método implementado por la estructura llamada "el maestro del año" o "empleado del año", como fue nombrada en la asamblea:

- Van a premiar al empleado del mes [risas].

- Les van a dar a los compañeros una sopa de su propio chocolate, porque los profes premian en el grupo al mejor, y lo ponen en el diploma y lo ponen en el cuadro de honor, a ver qué sienten maestros, eso hacemos, esa actividad, si hay colectivos escolares muy jodidos (A5, 23/05/2017).

En las asambleas se ha tomado muy en serio (y no tanto) analizar las acciones que emprende el nuevo gobierno estatal, que pretende ir dando soporte y validando la Reforma Educativa. Es ahí donde RESISSSTE ve una gran amenaza a la escuela pública. De esta técnica de validación se desprenden mecanismos de control que son matizados, aunque algunos de estos son cada vez más abiertos so pretexto de los procesos de la calidad total, como es el caso de la evaluación docente.

Como sostiene McLaren (1998), la cultura dominante ejerce control sobre clases o grupos subordinados a través de un proceso denominado hegemonía. Esta se refiere al mantenimiento de la 
dominación y el sometimiento por medio de distintas prácticas, que, de inicio, no son abiertamente físicas, sino más bien formas culturales mediadas con la ayuda de distintas instituciones políticas, pero, sobre todo, sociales. Las formas sociales son, precisamente, los principios que proveen y dan legitimidad a determinadas prácticas sociales. La hegemonía —continúa McLaren- es una lucha en la que el poderoso gana el consentimiento de los oprimidos, quienes ignoran que forman parte de este proceso. La hegemonía logra su cometido porque permea mediante el liderazgo moral e intelectual de la clase dominante sobre la clase subordinada, llevado a efecto no por medio de la coerción ni de la construcción intencionada de reglas y regulaciones, sino del propio consentimiento de los oprimidos (McLaren, 2011). Por tanto, la clase dominante no necesita emplear la fuerza para establecer la hegemonía debido a que la clase subordinada participa y asume muchos de sus valores y objetivos, los abraza e incluso los hace parte de las formas culturales y sociales en las que alimenta su cotidianidad. En el proceso de la reforma el adoctrinamiento ha sido abierto y directo, no solamente porque ha buscado impulsar los "valores" de la calidad total ligadas a prácticas empresariales, sino también ha organizado una formación de cuadros mediante la estructura, en particular con directores y supervisores de zona que llegaron a través del concurso de promoción, de los cuales, muchos de ellos se convirtieron en celosos guardianes del cumplimiento de la ley.

\section{LA EVALUACIÓN DOCENTE COMO UN MECANISMO DE CONTROL Y OPRESIÓN}

En la Reforma Educativa emprendida por el gobierno federal en 2012 se consideró como una de sus banderas principales el tema de la pobre calidad de la educación y, como antecedente natural, el bajo perfil/rendimiento de los docentes en los resultados académicos de los estudiantes. Esta reforma intentó validar frente a la sociedad la necesidad y urgencia de la evaluación docente, a la que llamó "evaluación de permanencia”, primero con el firme 
propósito de conocer las deficiencias de quienes estaban en servicio, ya que con base en las modificaciones realizadas al artículo 3 constitucional, en el nuevo sistema solo tendrían cabida los "idóneos" para desempeñar eficazmente la tarea de la enseñanza y rendir buenos resultados. Es de esta manera que poco a poco comenzó a entrar y establecerse el constructo de la evaluación docente, que ocupó mucho tiempo de análisis en las asambleas del movimiento magisterial RESISSSTE por considerarla punitiva y un atentado contra la estabilidad laboral del docente, una de las más grandes conquistas del gremio sindical.

La evaluación de permanencia se destacó por ser un proceso estresante, con un examen exageradamente extenso, tal como lo relatan miembros de la asamblea que lo vivieron:

- A mí sí se me hizo el examen muy, muy pesado, porque por ejemplo venía una lectura de una página y del otro lado unas respuestas, pues yo respondí más o menos bien unas 40, porque cuando llegas a la 50 - que eran unas 136- yo ya estaba muy cansado. Al último ya no leía el texto, me iba directamente a las preguntas...porque se cierra y corre el tiempo.

- Cuando yo llegué pero no [sic] había mucha gente, llegué a las 7, y había poca gente...y yo sí me fui temprano porque aunque no decía en ningún lado ya sabemos que tenemos que jugar el juego central de México...

- A nosotras nos dijo la aplicadora que el tiempo para ir al baño [se ríe] se descuenta del tiempo total...que se descontaba de tus 4 horas para hacer las 136 preguntas... por eso durante la aplicación del examen no tienes ni que tomar agua, porque hasta eso, si quieres tomar agua, debes levantarte porque no puedes entrar al aula con nada... (A1, 15/11/2016).

Aunque la evaluación se consideró como un "mal necesario", la forma en la que se desarrolló terminó por desembocar en un mecanismo de control por parte del Estado con el propósito cen- 
tral de retomar la rectoría sobre el sistema, que durante muchos años estuvo cooptado y controlado por el sindicato oficial y que, en el proceso de evaluación, ni las manos pudo o quiso meter. RESISSSTE protestó durante las primeras sesiones de examen en el exterior de los centros de aplicación, logrando que cientos de maestros rechazaran la realización del examen, acto que trajo amenazas y sanciones punitivas en la posterioridad, que derivó el cese (evitaron a toda costa llamarle 'despido') de al menos 11 maestros en el estado, 7 de Ciudad Juárez. El movimiento lo consideró una sanción ejemplar para "meter en cintura" a quienes se resistieron a cumplir las nuevas reglas:

Cuando nos preguntaron a nosotros si íbamos a tapar, cuando incluso aquí estuvimos de acuerdo en que tapáramos, dijimos qué pasa si los compañeros no se presentan... se los chingan, si los despiden... y no vamos a ir a tapar para que la autoridad se chingue a los maestros y luego la autoridad nos culpe a nosotros y los compañeros maestros despedidos nos reclamen a nosotros que no pudieron entrar por nuestra culpa... sea era muy, muy distinta esta aplicación a las anteriores... ahí iban los directores a regularizar su clave, iban los de segunda oportunidad para joderlos... no podíamos decir vamos a tapar para joderlos.... y la situación estaba muy clara, si tapamos la autoridad hubiera dicho "no te metes, te corremos"... ya hay 17 compañeros cesados... no están jugando (A1, 15/11/2016).

La idea que dio el gobierno a la sociedad consistía en que todos los docentes estaban siendo sometidos a una evaluación para conocer sus capacidades; sin embargo, esta era solo una idea, ya que en la realidad se evidenciaba la incapacidad de la estructura para evaluar a los docentes en servicio:

...ya que tanto se ha hablado de la evaluación como un aspecto trascendental de la reforma, pero solo se ha podido evaluar entre el $15 \mathrm{y}$ 20\% de los maestros en activo... entonces algo no está bien, parece que el sistema no tiene capacidad para hacerlo (A5, 23/05/2017). 
Entonces el movimiento reconoce que la evaluación no es la solución para el problema tan llevado y traído de la falta de calidad educativa, sino que es tan solo un mero pretexto para imponer un mecanismo de control:

Yo creo que ellos saben que no es la solución a la bronca, sino que es el pretexto para chingar a medio mundo, y no determina la evaluación al que es el mejor maestro, traen los compañeros lamentablemente un chingo de debilidades, el profe se hace en la práctica, con la teoría y la práctica pues, ahí se hace el maestro, ahí aprenden, no en el aula y a través de un examen teórico, donde buscas sacar un chingo de puntos buenos, lo que luego pasa con los directores, medio mundo, y los que pueden salir muy eficientes a madre eso no se refleja en los estudiantes (A5, 23/05/2017).

Esto se hizo de acuerdo con el impulso de una "nueva cultura docente", vinculada a procesos de calidad total que el gobierno del estado realizó para difuminar lo punitivo de la evaluación, entre estas conferencias y otras acciones impulsadas con ese fin. Aun y con estos procedimientos, la disidencia magisterial reconoce que los docentes no están conformes con las fórmulas que sigue la evaluación de permanencia y muchos están buscando caminos para evadir la valoración, entre estos, la jubilación:

Entonces se viene esta incertidumbre en varios compañeros que algunos andan buscando la forma de chisparse de la evaluación, por ejemplo, ahí en la escuela, pues aparece un compañero que le faltan dos años para jubilarse, entonces anda tratando de ver si se puede pensionar, o sea que si se pensiona se pensionaría con el 95\% del salario... y en esa dinámica están cayendo muchos compañeros (A5, 23/05/2017).

La visión de la evaluación como un mecanismo de opresión y de control que ejerce el Estado en contra de los docentes sigue presente en las reflexiones del grupo, como menciona uno de sus miembros: 
Independientemente de los procesos que siguen los compañeros que se vayan a jubilar, que van a resistir, que vayan a esperar, a reprobar, que sé yo, no lo van a evitar, quién sabe... lo que comentábamos en días pasados, el jugar con los tiempos políticos, quién sabe qué vaya a pasar el otro año en el 2018, no sabemos, pero sí habría que hacer acto de presencia, hacer acto de protesta, seguir denunciando esto, que se vea que hay inconformidad con esa pinche reforma que es una farsa, que la evaluación no resuelve la bronca... (A5, 23/05/2017).

Curiosamente, se analizaban estas situaciones que acontecían con los docentes, y muchos que podían jubilarse y optaron por quedarse a ejercer control fueron los supervisores y jefes de sector en el subsistema federal. Cuando estos fueron conminados a evaluarse, lo vieron como una afrenta, por lo que se reconocía que "los jefes quieren evaluar, pero no ser evaluados", ya que, sin criterios claros para la selección de docentes para la evaluación, se decía que las listas se "armaban" en las supervisiones escolares con dedicatoria. Ante esta situación, RESISSSTE reconocía la necesidad de convocar a los docentes que han sido llamados a evaluarse para realizar una reunión y hablarles de la resistencia: "buscar junto con ellos nuevas formas de resistencia... no pueden, no podemos doblar las manos tan fácil, jchingado!” (A5, 23/05/2017).

En este proceso tan poco claro, los docentes fueron los más afectados por el estrés y el miedo con que enfrentaban el inconveniente evaluativo, aunado a que directores de escuela se tomaron las atribuciones de "ejecutar" las notificaciones de evaluación a los docentes bajo su cargo, aun sin tener listas oficiales por parte del Servicio Profesional Docente.

No solo son los mecanismos de control y cómo las "autoridades" escolares ejercieron la tarea de notificar a los docentes que serían evaluados, sino que es de suma importancia reconocer lo que el conflicto obró en los docentes, como el aumento del estrés, el descuido de la tarea de la enseñanza por atender a la elaboración del proyecto de enseñanza y el estudio. Un caso que merece atención especial es el tratamiento dual hacia los docentes que ingresaron 
al sistema con la reforma, en primer lugar, porque les abrió la posibilidad para acceder a una plaza a egresados de universidades públicas y privadas, pero el proceso de seguimiento para lograr una basificación parcial de cinco años fue muy tortuoso.

Desde la visión de la realidad simbólica, la pedagogía crítica pretende reivindicar y resignificar la subjetividad, y es por ello que constantemente se trae a la palestra la denuncia de los dispositivos que pretenden homogenizar y estandarizar, acorde a la lógica del mercado capitalista. Si se pretende resignificar y reivindicar lo subjetivo, "se necesitan escenarios para la resistencia, donde se manifieste la heterogeneidad cultural y las nuevas configuraciones (construcciones) simbólicas y políticas" (D’Antoni et al., 2014, p. 50). Algunos teóricos de la pedagogía crítica, como McLaren (1998), consideran la doble perspectiva en la que deben analizarse la escuela y lo que sucede dentro y fuera de ella, tanto como mecanismo de clasificación en el que grupos seleccionados de estudiantes son favorecidos con base en la raza, la clase y el género, como en las agencias para dar poder social e individual. En estos análisis se tiene por sentado el papel del docente como un ente pasivo que instrumenta las políticas educativas y las aplica mediante rituales que va aprendiendo cuasi por ósmosis, sin embargo, desde nuevos escenarios se busca resignificar el rol docente a partir de la concienciación de su estado de opresión y como parte del entramado ideológico que busca mantener el establishment intacto.

\section{CONOCER, ANALIZAR Y ACTUAR EN CONSECUENCIA... LOS CAMINOS DE LA RESISTENCIA}

Dentro del movimiento se distinguen algunos líderes visibles, que han sido constantes con el paso de los años, han abonado a su consolidación y han sido reconocidos por los propios miembros de la disidencia. Destacan que RESISSSTE, tanto a nivel local como estatal, no tiene una estructura inamovible o vertical que tome decisiones, sino que el órgano máximo es la propia asamblea, de constitución colectiva y democrática. No obstante, se distingue 
que existe un grupo mayormente comprometido con las causas del movimiento. Se reconoce, entonces, que el máximo órgano de organización y toma de decisiones es la Asamblea Local, en la que se desarrolla la participación voluntaria y democrática, se toman las decisiones y se definen tanto los temas como las acciones que dan lugar a las acciones de la resistencia. La asamblea no tiene un orden estructurado y, por tanto, tampoco existe una agenda definida, pues esta se va construyendo a partir de los temas que ocupan el interés en el ámbito educativo local, estatal o nacional. Así pues, la información y su análisis son para el movimiento el arma más poderosa y el camino necesario para generar actos contestatarios o acciones de resistencia.

Es la asamblea la vía para organizar la resistencia a la información política-educativa que se genera en todos los niveles del país. Se empieza a dar información sobre la consulta popular que pretendía lanzar la CNTE a todo el país y que el RESISSSTE apoyaría, con el fin de construir una propuesta alternativa a la reforma peñista. En el estado, a través de las asambleas locales y medios alternativos, se empezó a "rolar" la propuesta de la CNTE para socializarla y reconstruirla; de este modo, el movimiento asumiría la propuesta como propia. No solamente se compartido la información en las asambleas, sino también en los grupos de WhatsApp, que son una vía de comunicación muy usual en las escuelas.

Un aspecto que ocupó mucho tiempo en los análisis del colectivo fue lo evidente del cambio en la relación entre el gobierno y los docentes, quedando de lado - o como mero observador- el sindicato:

En estos temas que hemos tocado, se centran en la Reforma Educativa, en la bronca no es lo que están haciendo en este momento, porque desde el principio lo dijimos muchas veces, pasa de ser una relación de bilateralidad a una relación meramente administrativa y en esa relación administrativa la voz es la del patrón nada más. Esta administración de Javier Corral definió que la permanencia debe ser de dos años para tener derecho a un cambio. Por primera vez en un documento formal, pero si analizamos la ley del Servicio Profesional 
Docente y los periodos de evaluación y cómo se adquiere una plaza, pues tiene toda la razón el gobierno del estado con todo lo que está haciendo, tiene toda la razón legal para hacerlo (A7, 11/07/2017).

Dentro de los caminos legales que siguió la reforma se derivó el cese de docentes que se rehusaron participar en el proceso de evaluación del primer grupo, dentro de estos, siete docentes de Ciudad Juárez, y de estos, tres participantes activas del grupo. Se ha dado difusión a través de grupos de WhatsApp y otras páginas sobre el seguimiento de las docentes cesadas con el fin de hacer presión y acelerar las audiencias en la Junta Conciliación y Arbitraje (JCyA). Se enviaron volantes digitales en grupos de WhatsApp para invitar a los docentes a apoyar una protesta frente a la JCyA. Ante esta situación, el sindicato dijo que no pasaría nada ni habría consecuencias punitivas de la reforma. Ellos, más bien, están ocupados con los reacomodos de su gente en direcciones y subdirecciones. Tal como se analiza en la asamblea la situación, no era para menos:

- Va en serio la cosa, es contra los charros nada más, ¿qué paso ahí?, hacia dónde nos va a llevar todo esto, ¿verdad?, no sé, pues sí hay que meterlo ahí a discusión, está interesante... "y yo me callo, yo sí me mantendría callado, sí tengo una pinche cola que me pisen, yo me escondo, me escondo y no digo ni madres", o sea a muchos representantes y líderes sindicales se los van a chingar fácil y si no lo sacan con esa madre, lo van a sacar con todas las demás tranzas que ha hecho en el sindicato, creo que así amarraron a los secretarios generales cuando detuvieron a Elba Esther... el contubernio con los gobernadores está en todos los estados, aquí nomás llega Serrano a la gobernatura $[$ sic] y no pasa esto...

- No pues no, no le andaban levantando la mano allá a Serrano en el centro de convenciones en Chihuahua... aquí se llevaron compañeros y tengo un director que pues dice él que no es sindicalista pero que hay que llevar la fiesta en 
paz, dice... entonces nos pone "nos están pidiendo cinco gentes del centro para que vayan a Chihuahua, se tienen que llevar su playera blanca y su mascada”, o no sé si les den la mascada allá, y "ándenles, ¿quién va?, casi de favor se los pido” (A3, 29/11/2016).

En tanto el sindicato intentaba llevar agua a su molino en medio de la gran confusión y dudas generadas por el proceso de evaluación y su repercusión en la estabilidad laboral, la asamblea abordaba la manera en la que el sindicato oficial buscaba acomodar a su gente en direcciones y subdirecciones comisionadas sin presentar un examen de oposición, las cuales luego serían validadas por las autoridades.

Aunado a estos amarres que estuvo conjugando el sindicato oficial, la SEP, a través de los medios de comunicación masiva, orquestó una campaña donde se buscaba —según se analizó en la asamblea- establecer un discurso legitimador de las acciones emprendidas en la Reforma, y, en todo caso, dejar mal parado al docente o grupos de profesores que decidieran resistirse a ser evaluados, y a la vez se reconoce que sin un salto cultural, con Reforma o sin Reforma, el docente seguirá haciendo lo mismo en su cotidianidad.

No es solamente el decreto o la consignación de leyes para cambiar la realidad que se vive en las escuelas en el día a día. RESISSSTE ha analizado la reforma peñista como un rotundo fracaso. Datos sobre la infraestructura, las condiciones deplorables en las que se encuentran muchas escuelas, dificultades para el acceso a la modernización y las nuevas tecnologías muestran que la reforma es, por ahora, solo discurso, y la realidad sigue mostrando las carencias y la falta de voluntad política.

Precisamente en la lucha contra la "cultura docente" se analizó el revés de la aplicación del examen de permanencia que convocó a los maestros de manera voluntaria, y, desde esta óptica, un primer triunfo de la resistencia en contra de la reforma y de la evaluación punitiva, tal como se analizó en una de las asambleas: 
- Hay dos informaciones que creo que pueden ser interesantes, una, aunque lo están anunciando como un logro pero es un fracaso, la evaluación esta del 2016, que fue de voluntarios y todo este rollo, a nivel nacional están diciendo que el 72\% acudió a la evaluación, y ahí en las noticias he estado escuchando que lo están anunciando como un logro, pero si el 100\% sacó el 52, pues están reprobados, es 5.2 (risas), entonces está interesante porque pues era voluntaria, como que hay un rechazo muy marcado.

- Aparte de ellos, muchos iban obligados.

- Sí, o sea, de los 10 mil y tantos que hubo evaluados en el país en esta etapa, eran que 600 y caso, no tengo los datos, pero sí es como el 52\% los que andan cacaraqueando, como un logro, pero es una franca cachetada que nos está dando el magisterio, esas resistencias a veces no las vemos en las calles, pero ahí se dio una pequeña muestra, pero esa es una información que sería interesante (A4, 13/12/2016).

Las situaciones cotidianas que viven los docentes, alumnos y padres de familia constituyen un insumo de análisis tan necesario como importante. El imaginario que intentó construir la reforma peñista se desdibujaba en el contexto escolar, en el aula. Se pueden dictar leyes por decreto, pero no desinstalar mágicamente la llamada cultura escolar; todo se deconstruye y reconstruye desde la visión - velada o consciente- del currículo oculto. Es por ello que se considera importante retomar análisis generados en las asambleas sobre las acciones cotidianas que se viven en las escuelas, desentrañar los porqués de los dispositivos instalados con la nueva reforma.

Aunque fuera de la jugada el sindicato oficial siguió ejerciendo influencia sobre la estructura de base en las inspecciones escolares y en las escuelas, en concreto con directores afines, la reforma intentó desterrar de las prácticas escolares los arreglos en "lo oscurito" y la corrupción. A pesar de ello, en el contexto escolar se continuaron realizando acuerdos tácitos que beneficiaron a unos 
cuantos. Fueron apreciados por los docentes como formas de "darle la vuelta” a las nuevas reglas impuestas, como a continuación nos exponen los siguientes comentarios:

- Como la reforma ahora ya no permite - según - a los comisionados sindicales, pues los fueron "reinstalando" en las escuelas como directores o subdirectores, como un premio, pero sin ir a trabajar a las primarias... nada más iban a firmar a la semana, pero no saben en la que se meten los directores porque si llega a haber una revisión...

- Hay muchos muy calladitos que no están diciendo ni madres, por ejemplo, un maestro que viene de primaria tiene una clave de jefe de sector asignada de manera ilegal, no falta el maestro ese en aparecer como jefe de sector, la esposa es supervisora también sin concurso, y tanto pinche charro que sale de ahí de la sección que salen con supervisiones o salen con claves, se benefician los cabrones, entonces es poco, pero esos güeyes son bien descarados (A4, 13/12/2016).

Sin embargo, y en concordancia con los ideales de RESISSSTE, no se trata únicamente de ir contra la reforma y lo que perjudique a la educación pública, sino que lo importante es generar reflexiones sobre lo que los docentes suelen hacer mal y que fueron, en todo caso, las bases para una Reforma Educativa eminentemente laboral:

- Más allá de seguirle el juego al Estado, vale la pena que hagamos una reflexión de cómo los profes utilizamos el tiempo en el aula, porque no estamos con objetos, estamos con gente que piensa, a mí en lo particular sí me voy a poner a pasar lista, plebe por plebe y sé perfectamente quién es el que falta, y si no sé, nada más con que le diga a los plebes quién faltó, y se chingó, ese tiempo que te ibas a usar ahí por qué no te avientas una buena lectura o una buena actividad que les genere placer a los morros, 
en vez de que pierdas el tiempo, creo yo que tenemos que reflexionar sobre esa cuestión de la práctica...

- Sí, o que no son cosas en las cuales se pierde el tiempo, pero pueden convertirse en actividades formativas, porque fue cuando quitaron por ejemplo las activaciones físicas...

- Y es importante decir que, el aspirar a un proyecto distinto de educación desde una visión no empresarial, pasa por una revisión detallada de lo que hacemos en la escuela los profes, y eso está cabrón... (A5, 23/05/2017).

\section{DELINEANDO LAS ACCIONES CONTESTATARIAS Y DE RESISTENCIA ANTE EL EMBATE DE LA REFORMA EDUCATIVA}

Uno de los modelos teóricos que ofrece la posibilidad del análisis antes planteado es aquel de Willis (citado por Giroux, 2004) que sitúa a las escuelas como sitios de dominación y contestación. Desde esta perspectiva, la dominación nunca es total, ni tampoco impuesta a la gente. Tal idea demanda que los maestros examinen no solo los mecanismos de dominación que existen en las escuelas, sino profundizar en cómo dichos mecanismos son reproducidos y resistidos por los estudiantes a través de las experiencias vividas. Foucault nos recuerda que el poder no es un fenómeno estático, es, por el contrario, un proceso dialéctico que siempre está en juego de posibilidades.

Es fundamental analizar a las escuelas como sitios sociales en los que la clase, el género y las relaciones raciales que caracterizan a la sociedad dominante están toscamente reproducidas, ante ello la pretensión del estudio debe basarse en el desarrollo de prácticas educativas alternativas. Un primer paso para ello sería - como lo sustenta Giroux - enfocarse en las relaciones entre la cultura de la escuela y las dimensiones abiertas y cerradas del currículo, así como en las experiencias contradictorias vividas que alumnos y maestros llevan al plantel. En esta relación entre escuela, cultura y experiencias contradictorias, los maestros y estudiantes registran impresiones y texturas de la dominación y la resistencia (Giroux, 2004). 
Las implicaciones prácticas de estas observaciones sugieren que, dado que en parte los mecanismos de producción-reproducción y transformación están localizados dentro de la cultura dominante de las escuelas, los maestros deberían considerar críticamente de dónde viene esa cultura, la cultura de quién se pone en práctica, a los intereses de quién sirve, cómo se inscribe y se sostiene en el discurso y en las prácticas sociales. Como argumenta Giroux, lo que se tiene que explicar es la fuente y los elementos que constituyen la estructura de la cultura escolar, y, en el centro de esta, el rol del docente.

En el proceso de dominación sobresale la necesidad de un análisis dialéctico del poder, ya que el conflicto y la contradicción juegan sin duda un papel importante en el ejercicio del poder (Martínez, 2005). Para Michael Foucault: "el poder no se da, no se cambia ni se retoma sino que se ejercita, no existe más que en acto” (Citado por Martínez, 2005, p. 22). El poder, como sostiene Martínez (2005, p. 23): "es ante todo una relación social; es la actuación política de los sujetos sobre el mundo, enmarcados por la configuración de las clases sociales, luchando por llevar a cabo sus intereses". El poder produce saber, y poder y saber están implicados directamente. Foucault sostiene que no hay relación de poder sin creación consecuente de un campo de saber, ni saber que no suponga y no cree al mismo tiempo relaciones de poder, es decir, el poder se nutre de las relaciones sociales asimétricas, y alude necesariamente a los distintos actos de resistencia. (Foucault, citado por Grenz, 1997).

Las relaciones de poder se presentan necesariamente en la escuela, más cuando el sistema educativo busca implantar una ideología acorde con los intereses del poder hegemónico. Este proceso de implantación implica distintas formas de imposición, autoritarismo, disciplina y control burocrático. Lo que antes se analizaba en relación del docente-alumno, en virtud del primero como agente opresor, hoy los análisis lo van trasladando de manera paulatina al ámbito de relación docente-sistema, teniendo a este último como el ejecutor de las políticas neoliberales de costobeneficio con una lógica mercantilista que ha desencadenado en 
acciones de resistencia magisterial a partir de la concienciación de su rol de oprimido.

El concepto de prácticas de resistencia parte del análisis que Michel Foucault realiza sobre los nuevos movimientos sociales surgidos a partir de 1968, interesándose por las estrategias de oposición a una realidad que se asume como natural. Dichos movimientos tienen en común el hecho de plantear su lucha fuera de los criterios tradicionales de reivindicación que giraban, hasta entonces, en torno al esquema identidad-opresión-liberación. Es a través de sus reivindicaciones que se empieza a dotar de significado político a lo que hasta entonces era considerado del plano privado. De esta manera rompen con los límites de lo establecido como política, asumiendo que todo es político.

Desde Martínez (2005) la resistencia hace referencia al reconocimiento de un contrapoder colectivo, ejercido por los oprimidos. Sin embargo, la teoría de la resistencia no reconoce una relación mecánica entre opresor-oprimido, desde una visión unilateral del poder. Por el contrario, en la resistencia se destaca el papel de lucha que lega a desplegar el oprimido ante un sistema opresor (Martínez, 2005). Como bien lo plantea Martínez Escárcega: “debe reconocerse que no todas las resistencias que se presentan en el contexto escolar o fuera de él tienen carácter emancipador, y no todos los actos de oposición resultan actos de resistencia” (2005, p. 87).

Para efectos de este trabajo, es de vital importancia reconocer cuáles son las conductas de oposición y cuáles son actos de resistencia. Para hacer esta distinción, teniendo como base los planteamientos de Giroux, se transitará por otras propuestas desde las perspectivas de McLaren, Martínez y García para efectos de este trabajo de investigación.

Como se ha venido destacando, en RESISSSTE no existe una agenda específica para la discusión, el análisis y la conformación de las acciones de resistencia formal. Podría considerarse que su forma central de contestar ante el embate de la dominación es la asamblea local, que se celebra, dicho sea de paso, en una disposición arquitectónica propiedad del sistema que se reconoce como opresor. Estas asambleas se consideran, a la vez, como cepa 
de las acciones constantes de RESISSSTE, así como también su boletín de difusión bimensual llamado El Tábano, donde realizan planteamientos y posicionamientos públicos del movimiento que se generan en discusión en las asambleas. Este órgano de difusión hace gala de la sátira y el sarcasmo como forma de resistencia. En los actos contestatarios que va delineando el RESISSSTE se ponen de manifiesto la ideología y el trasfondo político vinculado a la Coordinadora Nacional de Trabajadores de la Educación (CNTE).

$\mathrm{El}$ movimiento de la disidencia responde con actos contestatarios en el contexto del debate sobre la doble función de la escuela, por una parte, como reproductora del statu quo (representado los intereses del poder hegemónico) y, por el otro, resistir produciendo autonomía para la emancipación. Esta última función de la escuela es donde se sitúa la pedagogía crítica, ya que intenta:

empoderar a los sujetos para que sean constructores de una nueva vida posible, puedan desarrollar su autonomía, sean capaces de cuestionar, desafiar la dominación, así como sus prácticas, normas, creencias y valores preestablecidos, y proponer construir alternativas de sociedades solidarias, justas, inclusivas, políticas que defiendan la vida planetaria como imperativo categórico (D'Antoni et al., 2014, p. 56).

Pero el panorama no es alentador. Los sectores dominantes del sector político, conformado por grupos neoconservadores y neolibertarios (mercantiles), pretenden implantar la dominación desde la escuela y que esta funcione según sus intereses, que refuercen el carácter legitimador y hegemonizante de la educación pública y privada, y, lo más grave, que sometan al educador y al educando a través del conocimiento y legislación oficial.

En la función empoderadora de la escuela y sus agentes se alude a la resistencia como una práctica reflexiva para comprender procesos sociales emergentes tanto en la propia escuela como en otros espacios institucionales, donde, tal como lo menciona D'Antoni, es frecuente observar la desobediencia de quienes se ven sometidos a prácticas opresoras. Es por ello que la pedago- 
gía crítica tiene, como fruto necesario, ser emancipadora, "forjando sujetos críticos, propositivos, democráticos y conscientes de la necesidad de participar en la solución de los problemas que abruman a la comunidad, región, país. Sujetos conscientes de las deficiencias y limitaciones del modelo de desarrollo imperante" (p. 57), el cual promueve diversas formas de dominación. La escuela, desde la función de emancipación, debe buscar un modelo de desarrollo alternativo, humanista, autónomo, inclusivo y utópico que favorezca la vida, como parte de una propuesta ético-política. Es desde esta óptica que se hace necesaria la resignificación del rol de un docente emancipado-emancipador.

A partir de esta visión se desprende la presente investigación, es decir, considerar al docente como agente consciente de su propia condición de oprimido y su transición a la emancipación mediante acciones contestatarias, traducidas en acciones de resistencia a través de la participación en la disidencia magisterial.

Como sostiene McLaren (1998), la cultura dominante ejerce control sobre clases o grupos subordinados a través de un proceso denominado hegemonía. Esta refiere al mantenimiento de la dominación y el sometimiento mediante distintas prácticas, que inicialmente no son abiertamente físicas, sino más bien formas culturales terciadas por medio de distintas instituciones políticas, pero, sobre todo, sociales. Las formas sociales son, precisamente, los principios que proveen y dan legitimidad a determinadas prácticas sociales. La hegemonía -continúa McLaren- es una lucha en la que el poderoso gana el consentimiento de los oprimidos, quienes lo son ignoran que forman parte de este proceso. La hegemonía logra su cometido porque permea mediante la dominación moral e intelectual de la clase dominante sobre la clase subordinada, llevado a efecto no por medio de la coerción ni de la construcción intencionada de reglas y regulaciones, sino mediante el propio consentimiento de los oprimidos (McLaren, 2011). Por tanto, la clase dominante no necesita emplear la fuerza para establecer la hegemonía debido a que la clase subordinada participa y asume muchos valores y objetivos de la clase dominante, los 
abraza e incluso los hace parte de las formas culturales y sociales en las que alimenta su cotidianidad.

Aunque en este proceso los propios medios de comunicación masiva han jugado un papel central, no lo hace sino con la perspectiva de la cultura dominante que busca establecer el significado y el significante de todo cuanto pasa en las relaciones sociales, enmascarando las relaciones de poder y haciendo uso velado de aparatos del Estado, tales como escuelas, instituciones gubernamentales y burocracias estatales. En este proceso hegemónico, sostiene Mclaren (2008), los significados establecidos suelen estar limpios de contradicciones, impugnaciones y ambigüedades. Sin embargo, la resistencia ocurre con mayor frecuencia en el dominio de la cultura popular. La cultura dominante rara vez tiene éxito en todos los frentes, ya que, por lo general, la gente resiste. Los grupos alternativos se las arreglan para encontrar diferentes valores y significados para hacer un contrapeso, desafiando necesariamente el establishment.

Con el fin de mostrar la forma en que se organizan las asambleas y los temas que se proponen y debaten, se muestran a continuación los pasajes de las asambleas, complementadas con comentarios que ayuden al lector a interpretar la manera en que se estructuras los actos contestatarios:

- ¿Qué compañeros... armamos el orden el día o más bien de la noche, qué le ponemos... nos metemos en un punto de información?, que más... ahí en información le metemos todo lo que tengamos pendiente. ¿Qué otra cosa?

- La ruta de mejora en torno a la reforma porque ahí hay que sacar las tareas.

- Muy bien porque ese punto le sacaremos lo del tercer foro de educación que será el 17 de noviembre. Tercer foro y de ahí algunas acciones, un acto político en la Junta de Conciliación y Arbitraje... ¿qué otro tema compañeros?, lo que crean importante que hay que informar (A1, 15/11/2016). 
En este contexto se revisaron no solamente las acciones de la ruta legislativa que la CNTE movilizaba por el país con el fin de hacer una contrapropuesta de Reforma Educativa:

- $\quad$ Pues ya ven todo el movimiento que se ha dado contra la Reforma Educativa, en su momento se trazaron 3 ejes, no... la ruta política en las calles... la ruta pedagógica, el estar trabajando por construir un proyecto alternativo... la ruta organizativa, pues seguir aglutinando más organizaciones y resistencias... bueno primero divulgar la propuesta y es recabar arriba de cien mil firmas para llevar la iniciativa a las cámaras y que se discuta, y entonces ya está la propuesta, ya está una calendarización

- Eso nos obliga primero a conocerla, para ver qué están proponiendo los compas.. de hecho esta propuesta fue construida con participación de mano chihuahuense... entonces eso nos obliga a conocerla, conocer la calendarización y asumir la recolección de las firmas... la tarea, con toda la actitud y pues a activarnos pues... porque de ahí se desprenderían muchas tareas... (A1, 15/11/2016).

Giroux sostiene que "El concepto de resistencia conlleva una problemática gobernada por supuestos que cambian el análisis de la conducta de oposición de los ámbitos teóricos del funcionalismo y de las corrientes principales de la educación, por los del análisis político" (2004, p. 77). Giroux plantea, asimismo, lo que desde su perspectiva son las acciones o los mecanismos de resistencia, a partir de una diferenciación entre las acciones inconscientes y las conscientes, por lo que desmarca las que llama "conductas de oposición" y "resistencia”, propiamente.

Considerando este marco de referencia, para efectos de este trabajo, y la pretensión de lograr una interpretación crítica de la resistencia, se consideró como eje articulador el concepto de acciones contestatarias planteado por García (2009), en la siguiente lógica: 
las conductas de oposición se configuran por un sentido retardatario, los actos de resistencia conducen hacia la emancipación. Ambas son contestatarias, se enfrentan al poder, tienen una carga política que las define; la primera busca ajustarse a la lógica de la dominación, mientras que la segunda, busca incesantemente transformarla radicalmente (p. 125).

En otras palabras, toda actuación de enfrentamiento al poder hegemónico resulta en una acción contestataria, con un trasfondo ideológico-político particular. No obstante, en la práctica se debe diferenciar de manera clara cuáles son actos de oposición y de resistencia. El reto de este trabajo de investigación radica en potenciar la transformación de los actos de oposición en acciones de resistencia a través de la reflexión crítica de sus motivaciones políticas.

RESISSSTE estructura sus mecanismos de resistencia a través de la construcción de una agenda que incluye los temas de interés vigentes en el contexto nacional, estatal y local, los cuales tienen afectación directa con el ámbito de la escuela, entendida no como un ente aislado, sino como una institución social que debe buscar, desde su misma organización interna (estructura, vinculación, praxis educativa y gestión), transformar sus prácticas para impactar en la comunidad. Las acciones de resistencia que se delinean incluyen diversas formas y fondos, desde los pronunciamientos ideológicos y políticos hasta lo ya conocido en los movimientos sociales como son las manifestaciones y acciones que implican salir a la calle y hacer visible, ante la comunidad, aquellas problemáticas que desde el statement se pretende invisibilizar para mantener la opresión de los agentes que deben seguir generando intereses para el poder hegemónico.

Los intereses del movimiento de la resistencia en Ciudad Juárez se orientan a desenmascarar los trasfondos ideológicos, políticos, sociales, económicos, culturales y educativos de la reforma emprendida por el gobierno federal desde 2012 y que ha pasado desde pronunciamientos y leyes hasta las acciones que han socavado y sometido a los docentes a una visión neoliberal y con una 
franca visión de privatización de la educación pública. La asamblea replanteó la necesidad de generar acciones de resistencia más amplias y contundentes:

Debemos movilizarnos fuerte, generar acciones más contundentes y avanzar a eso tan anhelado del pinche sistema de madrearse al sindicato, y que tiene elementos para madrearlo por tanto pinche corrupto... pero ¿quién sostiene al sindicato y a toda su estructura burocrática?, pues los jefes de sector, los supervisores... la última oxigenada que dieron los pinches charros, dijeron "pongamos en las subdirecciones de gestión a los políticos" y los mandan y los ponen ahí y se sacan esas pinches comisiones no sé de dónde, y ahora les dicen: "órale pues, pero nada más que le van a entrar ahora a concurso también”... les están desmantelando todo pero siguen agarrando posiciones y sacando provecho, ya lo estamos viviendo... (A8, 13/06/2017).

En suma, en la resistencia formal, al ser considerada la participación en la asamblea local, se discuten los temas que sus participantes creen importantes, tanto para discutirlos como para atenderlos mediante alguna acción de resistencia que en conjunto se construya. Los temas referentes a la Reforma Educativa y sus implicaciones en los ámbitos económicos, políticos, culturales, sociales y educativo han ocupado la atención y la acción de RESISSSTE en Ciudad Juárez.

\section{HALLAZGOS Y CONCLUSIONES}

A lo largo de la exposición de ideas y datos empíricos recabados se ha pretendido dilucidar aspectos importantes de vinculación entre las motivaciones de la disidencia magisterial con los procesos hegemónicos de dominación y la forma en que se constituyen las acciones contrahegemónicas que dan como resultado conductas de oposición o bien mecanismos de resistencia. Es desde los planteamientos teóricos de Henry Giroux (2004) que se aviene 
la necesidad de destacar lo que desde su visión se concreta en conductas de oposición, o bien, en mecanismos de resistencia. En el movimiento social, del que forma parte el movimiento de la disidencia en Ciudad Juárez, existen, tanto por interés como por necesidad, acciones que buscan desestabilizar los dispositivos ideológicos que, por lo general, el Estado -y los poderes hegemónicos de facto- despliega para perpetuar el status de opresión a partir de la inconciencia de la vida económica, política, social, cultural y educativa de la escuela.

Existe la necesidad de reflexionar de manera crítica lo que sucede en la escuela, en donde convergen un sinnúmero de intereses que subyacen en la lucha de poder: implicaciones hegemónicas, la implantación de una ideología específica que permita perpetuar la opresión como se conoce hoy. Debido a lo anterior, se plantea a continuación una serie de puntos a manera de conclusiones y hallazgos que permitan un acercamiento a las acciones desde la teoría de la resistencia en el marco de la pedagogía crítica.

Tal y como se ha considerado por los teóricos de la resistencia, una característica muy particular de RESISSSTE en Ciudad Juárez es que no está solo en la protesta, sino que se ha vinculado con otras causas sociales que permiten alimentar una visión mucho más amplia de la tarea educativa y emancipatoria de la escuela. Si se parte de los planteamientos de Melucci (1980), puede considerarse que el movimiento de la disidencia magisterial gestado en la ciudad muestra una actuación conjunta, intencionada, desarrollada en la lógica de la reivindicación, de la defensa de un interés o de una causa o, incluso, puede decirse que ha formado una empresa colectiva que tiene por objetivo establecer un "nuevo orden" en su espacio laboral y sindical. Desde este enfoque, es posible destacar que RESISSSTE considera como suyas las tres premisas fundamentales de lucha a nivel político y educativo de la Coordinadora Nacional de Trabajadores de la Educación (CNTE): democratización del sindicato, democratización de la escuela -como entidad transformadora- y democratización del país, a partir de la transformación de todas sus estructuras. 
La Reforma Educativa ha significado para la movilización docente un catalizador de acciones de oposición y lucha permanente. Una de sus banderas en el conflicto ha sido la serie de cambios en el artículo $3^{\circ}$ (fracciones III, VII y VIII; se agrega la fracción IX) y $73^{\circ}$ (fracción XXV) constitucionales, que versan:

El Estado garantizará la calidad en la educación obligatoria de manera que los materiales y métodos educativos, la organización escolar, la infraestructura educativa y la idoneidad de los docentes y los directivos garanticen el máximo logro de aprendizaje de los educandos.

Esto, para los grupos de resistencia, representa una intromisión de la eficiencia empresarial en el marco de las políticas económicas neoliberales. En tanto que el eje 3, Formación y desarrollo de los docentes, indica que el Servicio Profesional Docente estará basado en el mérito, es uno de los aspectos que ha ocupado gran parte de las discusiones en las asambleas, así como las acciones de resistencia más evidentes en la lucha contra la Reforma Educativa.

La disidencia magisterial se ha asumido, por el grupo consolidado en Ciudad Juárez y sus simpatizantes, como una filosofía y estilo de vida, una forma de actuar y de pensar que deben concretarse en acciones emancipatorias. En concordancia con los planteamientos de la teoría crítica en educación, el movimiento de resistencia se origina y se fortalece a partir de su relación dialéctica con los procesos sociohistóricos, políticos, económicos, culturales que se viven tanto a nivel internacional, como nacional y por supuesto local.

Partiendo de los planteamientos de McLaren, en los actos de RESISSSTE se reconocen distintos planteamientos y posturas de la praxis crítica, concretadas en diferentes visiones de acción/vinculación, por lo que se destacan coincidencias con la pedagogía crítica feminista, marxista, enfoque humanista desde la orientación marxista, constructivismo crítico, teoría social posmoderna, entre otras. Es importante destacar los puntos de coincidencia entre las acciones de la disidencia y los planteamientos de peda- 
gogía crítica, particularmente en aspectos como política, cultura y economía. Uno de los mayores retos de la pedagogía crítica es revelar y desafiar el papel que las escuelas y el rol que desempeñan en nuestra vida política y cultural, motivo por el que se discuten y se reflexionan las problemáticas que, a consideración, tocan fondo, o bien, afectan la vida de la escuela, y cómo afecta ésta, a su vez, a la vida social, tarea que sin duda ha asumido RESISSSTE como una de sus principales vías de la resistencia. De igual manera se han tomado reflexiones críticas sobre los detalles de lo que los estudiantes, maestros y otros agentes inmersos en el proceso de enseñanza-aprendizaje deben cometer juntos y de las políticas culturales que tales prácticas sostienen. Se parte de la premisa de que no se puede hablar de prácticas de enseñanzas sin hablar de política.

Continuamente la formación y el rol docente se traen a la palestra. Para el movimiento de la resistencia pareciera que la autoridad educativa busca la implantación-implementación de una Reforma Educativa “a prueba de maestros", reduciéndolo de esta manera a un empleado semientrenado y mal pagado, al que se le ve desde una mirada utilitarista. Desde las acciones de RESISSSTE se busca hacer consciencia de esto a los docentes y sumarlos a la lucha en contra del poder hegemónico y todo lo que representa en la vida, tanto de las escuelas como de la sociedad.

La hegemonía logra su cometido porque permea mediante dominación moral e intelectual sobre la clase subordinada llevado a efecto no por medio de la coerción ni de la construcción intencionada de reglas y regulaciones, sino con el propio consentimiento de los oprimidos, es, por lo tanto, una tarea constante - tanto en el discurso como en la acción- El propósito de RESISSSTE ha sido develar lo que consideran atentados y atropellos contra el gremio docente y la manera en la que el sindicato oficialista ha contribuido a ello, aun contando con la complicidad de los propios sujetos acongojados. Se reconoce que aún en el grupo consolidado no existe homogeneidad en los supuestos ideológicos que dan sentido a las acciones, sin embargo, teniendo como catalizadores la discusión, la reflexión y la acción, ha logrado encontrar diferen- 
tes valores y significados para hacer un contrapeso y desafiar al estado actual de las cosas.

Parte de la acción concienciadora del movimiento disidente ha implicado hacer evidente la dominación presente en el sistema educativo, a nivel macro, en las supervisiones escolares y las escuelas, cuando se imponen relaciones asimétricas de manera abierta, en donde se privilegian a unos grupos por encima de otros, ya sea afines al sindicato o a la estructura oficial.

En los planteamientos, una constante radica en desentrañar la función negativa de la ideología como en su legitimación: la implantación de la Reforma Educativa, autodenominándose legítima, eminentemente justa o digna de respeto, o bien, la disimulación, cuando las relaciones de poder son veladas, negadas, ocultas de diferentes modos. En las asambleas, estas toman forma y apellido y, por lo general, se delinean estrategias de acción. Considerando los postulados de Althusser (citado por Giroux, 2004), RESISSSTE concuerda en que para mantener el sistema de producción existente y los arreglos de poder se depende tanto del uso de la fuerza como del uso de la ideología. Sin embargo, es importante destacar que los supuestos ideológicos y/o políticos del movimiento no pueden precisarse de manera puntual. No obstante, se toman a modo de base las formas discursivas, como el significado y el significante de los planteamientos y acciones de la resistencia. Es posible tomar en cuenta que estas premisas oscilan entre los planteamientos marxistas y marxistas-leninistas. Del marxismo se destacan los discursos referentes a hacer visible la lucha de clases, particularmente la que surge entre explotadores y explotados, los de arriba y los de abajo; desde la posición leninista, el alzamiento esboza distintas estrategias sociales, políticas, económicas e ideológicas -aún no muy claras- que posibilitan avanzar a desmontar el sistema capitalista, partiendo de hacer evidente lo subyacente. Partiendo de estas bases, RESISSSTE ha declarado continuamente que la lucha del gremio magisterial no debe concentrarse solo en lograr victorias o cambios a nivel económico - que, por lo general, plantea el sindicato oficialista-, puesto que ello conduciría a la conformación de movimientos sindicalistas- 
reformistas que, más temprano que tarde, lo único que lograrían sería afianzar el dominio del sistema capitalista, lo que ha sido evidente desde la privatización del ISSSTE en 2008 y con el inicio y consolidación de la Reforma Educativa. Acorde con estos pensamientos, RESISSSTE ha tomado como misión cambiar el metabolismo del sistema, las relaciones y medios de producción, a fin de desmontar el trasfondo de las acciones que se han emprendido contra el gremio magisterial derivadas de la Reforma Educativa.

En concordancia con los planteamientos de la pedagogía crítica el movimiento RESISSSTE asume el repensar la escuela en términos de las relaciones de poder y en contra del determinismo económico y social. Además de plantear una reconcepción del papel de la escuela, de la función docente, y del compromiso educativo en la constitución del ciudadano. El movimiento de la disidencia ha asumido la inquietud por el análisis sobre la cultura dominante, las culturas subordinadas y las subculturas, y en ese camino reencontrar la identidad del docente ante los retos de los planteamientos neoliberales.

Refiriendo las teorías de la reproducción, el movimiento se ha posicionado en el replanteamiento del problema, específicamente de entender cómo funcionan las escuelas en beneficio de la sociedad dominante, y plantea reflexiones del modo en el que poder es usado para mediar entre las escuelas y los intereses del capital. Según los planteamientos de prácticas de resistencia (Ranciere, Touraine, Giroux, Bourdieu, etc.), los desafíos de la nueva sociedad deben ser respondidos luego de una crítica social de los contenidos que definan tal intervención al enfrentarse a las nuevas formas de configuración de lo social. Desde cualquier marco teórico, el conocimiento de las actuales transformaciones y del deber éticopolítico de tomar partido y participar en el desencadenamiento del cambio va a depender de la efectividad de la intervención. Miembros de RESISSSTE reconocen no tener conciencia ni del alcance ni del impacto de las acciones contrahegemónicas que han emprendido. De acuerdo con la evidencia empírica que fue posible levantar en el trascurso del desarrollo de esta investigación 
se destacan reflexiones sobre los tres ejes básicos en los cuales se sustenta la teoría base de las prácticas de resistencia:

1. Diversidad e identidades en los procesos de resistencia al sistema de dominación múltiple del capitalismo global; el movimiento RESISSTE ha logrado avanzar en la articulación de las luchas, y se considera que tiene como tarea pendiente avanzar en saberes, cosmologías, culturas y perspectivas libertarias, es decir, establecer bases ideológicas, políticas y teóricas que orienten y den sustento a las acciones de la resistencia.

2. El movimiento de la resistencia en Ciudad Juárez tiene como tarea pendiente consolidar estrategias de poder, política y lucha por la emancipación, que le permitan hacer frente a los desafíos frente a nuevos estímulos y realidades que plantea, de entrada, la Reforma Educativa-Laboral, así como

3. delinear alternativas claras frente a la cultura y la comunicación hegemónicas, lo que implica estrategias mucho más masivas y efectivas.

De acuerdo con Giroux (2004), sería de suma importancia para el logro de sus objetivos que el movimiento de la resistencia destaque en sus acciones la importancia del agenciamiento humano y la experiencia escolar como piedras angulares teóricas para analizar las ya complejas relaciones existentes entre las instituciones educativas y la sociedad dominante. En otras palabras, promover proyectos educativos alternativos que permitan plasmar en la realidad las ideas de prácticas transformadoras y particularmente emancipatorias. El agenciamiento refiere especialmente las nociones de conflicto, lucha y resistencia y sus efectos en la vida social colectiva.

Para definir si las acciones emprendidas por el RESISSSTE corresponden a conductas de oposición, o bien, a mecanismos de resistencia, de acuerdo con los planteamientos de Giroux se deben considerar cuatro categorías: Intencionalidad, conciencia, significado del sentido común, así como la naturaleza y valor del 
comportamiento no discursivo. De acuerdo con los planteamientos de Giroux (2004), se puede mencionar que:

- En las acciones que delinea y pone en práctica el movimiento la intencionalidad está orientada de manera clara y consciente con fines emancipatorios.

- En lo que respecta a la conciencia, las acciones buscan traer a la luz la opresión a partir de la conciencia de la situación de opresión que se experimenta.

- Para fortalecer el significado del sentido común, es importante tomar y hacer conscientes los anclajes de la teoría crítica en educación y a partir de ello definir un aparato crítico que permita delinear acciones de resistencia con mayor significado e impacto social.

- En lo referente a la naturaleza y valor del comportamiento no discursivo, la evidencia empírica sugiere que es necesario e importante que RESISSSTE clarifique sus anclajes teórico, ideológico y político, no sólo en el grupo consolidado si no que refieran a principios y/o sustentos de las acciones de la resistencia.

Finalmente, considerando la visión de Michael Apple, el movimiento de la resistencia en Ciudad Juárez, que representa RESISSSTE, no aborda las problemáticas eminentemente educativas, como pudiera pensarse, sino que sus planteamientos buscan adentrarse en el contexto neoliberal y desentrañar la intríngulis de las políticas culturales para el siglo XXI, que incluso son apoyadas por organismos internacionales, para evitar que la construcción y significación del sentido común neoliberal gana fuerza mediante su confianza en la fuerza educativa de la cultura, para así asegurar un consentimiento generalizado. 


\section{REFERENCIAS}

Alvarez-Gayou, J. (2003). Cómo hacer Investigación Cualitativa. Fundamentos y Metodología, México: Paidós.

D’Antoni, M., Gómez, J., Gómez, L. y Soto, J. (2012). La escuela en cuestionamiento. Diálogos sobre la resistencia escolar en procesos pedagógicos emergentes, San José, Costa Rica: Editorial Arlequín.

García, R. (2011). Un acercamiento político a las prácticas contestatarias en los espacios escolares. (Tesis Doctoral). Universidad de Tijuana, Tijuana, México.

Giroux, H. (2004). Teoría y resistencia en educación, México: Siglo XXI/UNAM.

LaClau, E. y Mouffe, C. (1987). Hegemonía y estrategia socialista: Hacia una radicalización de la democracia, Madrid: Siglo XXI.

Martínez Escárcega, R. (2005). Educación, poder y resistencia. Una mirada crítica a la vida escolar, Parral, Chihuahua: Doble Hélice Editores/Universidad Pedagógica Nacional.

McLaren, P. (1998). La vida en las escuelas: una introducción a la pedagogía crítica en los fundamentos de la educación. México: Siglo XXI.

McLaren, P. y Farahmandpur, R. (2011). La enseñanza contra el capitalismo global y el nuevo imperialismo: una pedagogía crítica, Madrid: Editorial Popular.

Roel, V. (1981). Socialismo y educación: posición socialista ante la reforma educativa, Lima: Maguiña Editores.

Schmuck, R. (1997). Practical action research for change, Arlington Heights, IL: IRI/Skylight Training and Publishing.

Documentos primarios

Entrevista a profundidad a "Manuel", participante activo del RESISSSTE. Realizada el 09/12/2016. Referencia (E1, 09/12/2016). Entrevista a profundidad a "José", participante activo del RESISSSTE. Realizada el 05/02/2017. Referencia (E2, 05/02/2017). Entrevista a profundidad a "Víctor", participante activo del RESISSSTE. Realizada el 12/ 03/2017. Referencia (E3, 12/ 03/2017). 
Asamblea ordinaria RESISSSTE llevada a cabo el 15/11/2016. Referencia (A1, 15/11/2016).

Asamblea ordinaria RESISSSTE llevada a cabo el 22/11/2016. Referencia (A2, 22/11/2016).

Asamblea ordinaria RESISSSTE llevada a cabo el 29/11/2016. Referencia (A3, 15/11/2016).

Asamblea ordinaria RESISSSTE llevada a cabo el 13/12/2016. Referencia (A4, 15/11/2016).

Asamblea ordinaria RESISSSTE llevada a cabo el 23/05/2017. Referencia (A5, 23/05/2017).

Asamblea ordinaria RESISSSTE llevada a cabo el 30/05/2017. Referencia (A6, 30/05/2017).

Asamblea ordinaria RESISSSTE llevada a cabo el 23/05/2017. Referencia (A7, 06/06/2017). 